\title{
Chlorhexidine-alcohol versus Povidone-Iodine-alcohol for surgical site antisepsis in caesarean section
}

\author{
Vishnu Priya Kesani*, Sruthi Talasila, Sheela S. R.
}

Department of Obstetrics and Gynecology, Sri Devraj Urs Medical College, Kolar, Karnataka, India

Received: 13 March 2019

Accepted: 22 March 2019

\section{*Correspondence:}

Dr. Vishnu Priya Kesani,

E-mail: vishnukesani@gmail.com

Copyright: () the author(s), publisher and licensee Medip Academy. This is an open-access article distributed under the terms of the Creative Commons Attribution Non-Commercial License, which permits unrestricted non-commercial use, distribution, and reproduction in any medium, provided the original work is properly cited.

\begin{abstract}
Background: Caesarean section is one of the most common procedures performed. Recent studies found that surgical-site infection (SSI) was the most common healthcare-associated infection. Authors hypothesized that optimization of preoperative skin antisepsis may decrease postoperative infections. The objective was to establish the efficacy of chlorhexidine-based antiseptic protocol versus povidone-iodine protocol in reducing SSI for patients undergoing caesarean deliveries.

Methods: This is a randomized prospective study conducted from April 2017 to September 2017 at a tertiary care center in India. Women who underwent caesarean sections were allocated into either group. Enrolled patients were randomly assigned to have the surgical site painted with chlorhexidine-alcohol preparation or painted with a solution of $10 \%$ povidone-iodine and then with surgical spirit. The outcomes were any SSI occurring within a week or during the 30 day follow up period of the surgery including any of: superficial or deep surgical site infection, or endometritis, according to Centers for Disease Control and Prevention definitions.

Results: A total of 560 subjects (273 in the chlorhexidine group and 287 in the iodine group) qualified for the study. The number of surgical-site infection was significantly lower in the chlorhexidine group than in the iodine group (6.95\% vs. $14.28 \% ; \mathrm{P}=0.005)$. Chlorhexidine-alcohol was significantly more protective than iodine-alcohol against both superficial incisional infections $(5.49 \%$ vs. $10.10 \%, \mathrm{P}=0.03)$ and deep incisional infections $(1.46 \%$ vs. $4.18 \%$, $\mathrm{P}=0.04)$.

Conclusions: This study highlighted that Chlorhexidine-alcohol provided superior skin antisepsis in comparison to povidone iodine-alcohol.
\end{abstract}

Keywords: Chlorhexidine, Preoperative antisepsis, Surgical-site infection

\section{INTRODUCTION}

Caesarean section is one of the most common procedures performed and its rate is on the rise. Surgical site infections (SSIs) are infections of the incision or organ or space that occur after surgery. ${ }^{1}$ Though advances such as improved operating room ventilation, methods of sterilization, surgical technique, and availability of antimicrobial prophylaxis have been made in infection control practices SSIs still remain a substantial cause of morbidity, prolonged hospitalization, and death. SSI is associated with a mortality rate of $3 \%$. Also, SSIs are the costliest Hospital acquired infections with considerable economic ramifications and an additional burden of increased hospital stay. ${ }^{2}$

Skin is a major source of pathogens that cause surgicalsite infection. The integrity of the skin is disturbed by the 
incision during surgery, posing a risk of infection; thus, organisms living in harmony in the skin near the incision can cause an SSI. ${ }^{3}$ Optimization of preoperative skin antisepsis may decrease postoperative infections. Despite the implementation of preoperative preventive measures, which include skin cleansing with Povidone-IodineAlcohol, surgical-site infections still occur. So, authors postulated that improving skin antisepsis would decrease surgical-site infections. ${ }^{4}$

Literature suggests that iodine reacts with bacterial amino acids and fatty acids resulting in the destruction of their cellular structures and enzymes, while; chlorhexidine gluconate, causes the destruction of bacterial cell membranes leading to leakage of cellular constituents and coagulation of cell contents. ${ }^{5}$

The objective of this study was to establish the efficacy of chlorhexidine-based antiseptic protocol versus povidone-iodine protocol as a preoperative skin preparation in reducing SSI for patients undergoing caesarean deliveries.

\section{METHODS}

This is a randomized prospective study conducted from April 2017 to September 2017 at the Department of Obstetrics and Gynaecology at Sri Devaraj Urs Medical College, a tertiary care hospital in at Kolar, Karnataka.

\section{Inclusion criteria}

- Patients 18 years of age or older who were undergoing caesarean sections were eligible for enrolment in the study.

\section{Exclusion criteria}

- Exclusion criteria were a history of allergy to chlorhexidine, alcohol, or iodophors; evidence of infection at or adjacent to the operative site; and the perceived inability to follow up the patient's course for 30 days post-surgery.

A total of 592 patients were eligible for the study, 32 patients were lost to follow up, and so 560 patients were considered in the final analysis. 273 patients in the chlorhexidine- alcohol group and 287 patients in the povidone-iodine alcohol group were considered for the final analysis.

Patients enrolled in the study were randomly assigned in a 1:1 ratio to be preoperatively scrubbed at the surgical site by either the chlorhexidine alcohol (2\% chlorhexidine gluconate and 70\% isopropyl alcohol) or the povidone iodine-alcohol (10\% povidone-iodine and then with surgical spirit).
Patients were preoperatively evaluated with complete history, general physical and systemic examination, and complete hemogram and relevant biochemical parameters. Both the groups of patients received preoperative per protocol prophylactic Intravenous antibiotics with $1 \mathrm{~g}$ Ceftriaxone.

Vital signs and surgical site were examined at least once a day while the patient was hospitalized during the first week post-surgery, and on discharge, patients were followed upon a weekly basis for the 30 day follow up period or as an when symptoms of wound infection developed. Clinically relevant microbiological samples were sent for culture and sensitivity testing from surgical site infection site. The criteria for citing an infection was as per the Centers for Disease Control definitions of SSIs. ${ }^{1}$

\section{Statistical analysis}

Superficial infection, deep infection and was consider as primary outcome variable, antiseptic was considered as primary explanatory variable. Descriptive analysis was carried out by mean and standard deviation for quantitative variables, frequency and proportion for categorical variables. Data was also represented using appropriate diagrams like bar diagram and pie diagram. The association between categorical explanatory variables and quantitative outcome was assessed by comparing the mean values. The mean differences along with their 95\% CI were presented. Independent sample ttest was used to assess statistical significance. The association between explanatory variables and categorical outcomes was assessed by cross tabulation and comparison of percentages. Odds ratio along with $95 \%$ $\mathrm{CI}$ is presented. Chi square test was used to test statistical significance. $\mathrm{P}$ value $<0.05$ was considered statistically significant. IBM SPSS Version 22.0. IBM Corp Armonk, NY; 2013 was used for statistical analysis.

\section{RESULTS}

A total of 560 subjects (273 in the chlorhexidine group and 287 in the iodine group) qualified for the study (Table 1).

Table 1: Distribution of patients into study groups

\begin{tabular}{|l|l|l|}
\hline Antiseptic & Frequency & Percentage \\
\hline Chlorhexidine & 273 & 48.75 \\
\hline Betadine & 287 & 51.25 \\
\hline
\end{tabular}

The patients in both groups were similar with respect to demographic data with no significant difference in relation to age, Body mass index (BMI), parity, previous abdominal surgery, type of the Caesarean section, and the duration of surgery (Table 2). 
Table 2: Baseline characteristics of patients in the study groups.

\begin{tabular}{|c|c|c|c|}
\hline Characteristic & Chlorhexidine & Povidone Iodine & P value \\
\hline Age (years) & $22.6 \pm 2.7$ & $22.63 \pm 2.57$ & 0.88 \\
\hline BMI & $21.86 \pm 2.23$ & $21.94 \pm 2.25$ & 0.67 \\
\hline \multicolumn{4}{|l|}{ Parity $[n(\%)]$} \\
\hline Primigravida & $122(44.7 \%)$ & $127(44.3 \%)$ & 0.92 \\
\hline Multigravida & $151(55.3 \%)$ & $160(55.7 \%)$ & \\
\hline \multicolumn{4}{|c|}{ Previous abdominal surgery [n (\%)] } \\
\hline Yes & $111(40.7 \%)$ & $118(41.1 \%)$ & 0.91 \\
\hline No & $162(59.3 \%)$ & $169(58.9 \%)$ & \\
\hline Duration of surgery (minutes) & $66.52 \pm 8.34$ & $66.65 \pm 8.28$ & 0.86 \\
\hline \multicolumn{4}{|l|}{ Type of caesarean section [n (\%)] } \\
\hline Emergency & $241(88.27 \%)$ & $254(88.50 \%)$ & 0.93 \\
\hline Elective & $32(11.72 \%)$ & $33(11.49 \%)$ & \\
\hline
\end{tabular}

Table 3: Proportion of patients with surgical site infection, according to type of infection.

\begin{tabular}{|l|l|l|l|}
\hline Type of infection & Chlorhexidine-alcohol n & Povidone Iodine-alcohol & P value \\
\hline Overall infection rate & $19(6.95 \%)$ & $41(14.28 \%)$ & 0.005 \\
\hline Superficial incisional infection & $15(5.49 \%)$ & $29(10.10 \%)$ & 0.043 \\
\hline Deep incisional infection & $4(1.46 \%)$ & $12(4.18 \%)$ & 0.05 \\
\hline Surgical site infection <48hrs & $2(0.73 \%)$ & $2(0.69 \%)$ & 0.960 \\
\hline Surgical site infection 48hrs-1week & $14(5.12 \%)$ & $31(10.80 \%)$ & 0.014 \\
\hline Surgical site infection <1 week & $16(5.86 \%)$ & $33(11.49 \%)$ & 0.018 \\
\hline Surgical site infection 8 days-30 days & $3(1.09 \%)$ & $8(2.78 \%)$ & 0.150 \\
\hline
\end{tabular}

Table 4: Comparison of culture reports between two study group $(\mathrm{N}=60)$.

\begin{tabular}{|c|c|c|c|c|}
\hline \multirow{2}{*}{ Culture organism } & \multicolumn{2}{|c|}{ Antiseptic } & \multirow{2}{*}{$\begin{array}{l}\text { Chi } \\
\text { square }\end{array}$} & \multirow{2}{*}{ P-value } \\
\hline & Chlorhexidine(N=19) & Povidone Iodine $(\mathrm{N}=41)$ & & \\
\hline Escherichia coli & $8(42.10 \%)$ & $11(26.82 \%)$ & \multirow{8}{*}{4.668} & \multirow{8}{*}{0.700} \\
\hline Acinetobacter & $2(10.52 \%)$ & $3(7.317 \%)$ & & \\
\hline Staph aureus & $2(10.52 \%)$ & $8(19.51 \%)$ & & \\
\hline Staph epidermidis & $0(0 \%)$ & $5(12.19 \%)$ & & \\
\hline Pseudomonas & $1(5.263 \%)$ & $2(4.878 \%)$ & & \\
\hline Skin commensals & $3(15.78 \%)$ & $5(12.19 \%)$ & & \\
\hline Klebsiella & $0(0 \%)$ & $1(2.44 \%)$ & & \\
\hline No growth & $3(15.78 \%)$ & $6(14.63 \%)$ & & \\
\hline
\end{tabular}

The overall rate of surgical-site infection was significantly lower in the chlorhexidine-alcohol group than in the povidone iodine- alcohol group (6.95\% vs. $14.28 \% ; \mathrm{P}=0.005$ ). similarly, chlorhexidine-alcohol group was also associated with significantly fewer superficial incisional infections $(5.49 \%$ vs. $10.10 \% ; \mathrm{P}=0.043)$ and deep incisional infections ( $1.46 \%$ vs. $4.18 \% ; \mathrm{P}=0.05)$ between the study groups. Chlorhexidine-alcohol was associated with significantly fewer infections within a week postoperatively $(5.86 \%$ vs. $11.49 \% ; \mathrm{P}=.01)$. Similar results were observed in the study during the 30-day follow-up period (1.09\% vs. $2.78 \% ; \mathrm{P}=0.15)$ though these values were not statistically significant (Table 3 ).

Culture of the surgical site in 51 of 60 infected patients yielded a growth of organisms, and similar proportions of infected patients in the two study groups (16 of 19
[84.21\%] in the chlorhexidine- alcohol group and 35 of 41 [85.36\%] in the povidone-iodine alcohol group) had an identifiable cause of infection. While, isolates from the surgical site of $15.78 \%$ in the chlorhexidine- alcohol group and $14.63 \%$ in the povidone-iodine alcohol group showed no growth of organisms (Table 4). No allergic reactions were seen in either group.

\section{DISCUSSION}

Surgical site infections are persistent and preventable health care-associated infections. There is increasing demand for evidence-based interventions for the prevention of SSI. The prevention of SSI is increasingly important as the number of surgical procedures performed is on the rise and associated morbidity for the patients due SSI and its impact the overall cost of 
healthcare is high. Considering the need for establishment of preventive strategies for SSI control the present study aimed at establishing an effective preoperative skin antiseptic at the surgical site. The results of the present study were consistent with the study conducted by Darouicheet al and Amer-Alshiek et al who reported similar a similar reduction in the rate of SSI. ${ }^{4,6}$ However, in studies conducted by Menderes $G$ et al, Elshamy et al and Springel EH et al, no significant difference was shown between the rate of SSI between either groups and the results were comparable. ${ }^{7-9}$ In the present study, the overall rate of SSI was lower with Chlorhexidine-alcohol group both within a week and during the 30 day follow up period in comparison to the Povidone-Iodine alcohol group for both superficial incisional and deep incisional infections.

In the present study, there were no significant differences in the frequency of isolating certain categories of organisms or particular organisms in the Chlorhexidinealcohol group as compared with the Povidone-Iodine alcohol group, with the exception of streptococci epidermidis, which was not isolated in the former group (0 vs. 5 of 41 [12.19\%]) and Klebsiella species group (0 vs. 1 of 41 [2.44\%]). Escherichia coli was the commonest organism isolated from both the groups. Giacometti et al, concluded that iodine is an effective broad-spectrum bactericide, also being effective against yeasts, molds and protozoans. $^{10}$ Fitzgerald et al, remarked that chlorhexidine is a chemical antiseptic and that it is effective against both Gram positive and Gram-negative bacteria, although it's effect against fungi and other pathogens were to be investigated. ${ }^{11}$

\section{CONCLUSION}

Preoperative cleansing of the patient's skin with Chlorhexidine-alcohol is superior to cleansing with Povidone-iodine for preventing surgical-site infection after clean contaminated surgery such as caesarean section.

\section{Funding: No funding sources}

Conflict of interest: None declared

Ethical approval: The study was approved by the Institutional Ethics Committee

\section{REFERENCES}

1. National Healthcare Safety Network, Centers for Disease Control and Prevention. Surgical site infection (SSI) event. Available at: http://www.cdc.gov/nhsn/pdfs/pscmanual/9pscssicur rent.pdf.
2. Berríos-Torres SI, Umscheid CA, Bratzler DW, Leas B, Stone E, Kelz R, et al. Centers for Disease Control and Prevention Guideline for the Prevention of Surgical Site Infection, 2017. JAMA Surg. 2017;152:784-91.

3. Wenzel R. Surgical site infections and the microbiome: An updated perspective. Infect Control Hosp Epidemiol. 2019:1-7.

4. Darouiche RO, Wall Jr MJ, Itani KM, Otterson MF, Webb AL, Carrick MM, et al. Chlorhexidinealcohol versus povidone-iodine for surgical-site antisepsis. $\mathrm{N}$ Engl J Med. 2010;362:18-26.

5. Culligan PJ, Kubik K, Murphy M, Blackwell L, Snyder J. A randomized trial that compared povidone iodine and chlorhexidine as antiseptics for vaginal hysterectomy. Am J Obstet Gynecol. 2005;192:4225 .

6. Amer-Alshiek J1, Alshiek T, Almog B, Lessing JB, Satel A, Many A, et al. Can we reduce the surgical site infection rate in cesarean sections using a chlorhexidine-based antisepsis protocol? J Matern Fetal Neonatal Med. 2013;26:1749-52.

7. Menderes G, Athar Ali N, Aagaard K, SangiHaghpeykar H. Chlorhexidine-alcohol compared with povidone-iodine for surgical-site antisepsis in cesarean deliveries. Obstet Gynecol. 2012;120:103744.

8. Elshamy E, Ali YZA, Khalafallah M, Soliman A. Chlorhexidine-alcohol versus povidone-iodine for skin preparation before elective cesarean section: a prospective observational study. J Matern Fetal Neonatal Med. 2018;18:1-5.

9. Springel EH, Wang XY, Sarfoh VM, Stetzer BP, Weight SA, Mercer BM. A randomized open-label controlled trial of chlorhexidine-alcohol vs povidone-iodine for cesarean antisepsis: the CAPICA trial. Am J Obstet Gynecol. 2017;217:463.e1-e8.

10. Giacometti A, Cirioni O, Greganti G, Fineo A, Ghiselli R, Del Prete MS, et al. Antiseptic compounds still active against bacterial strains isolated from surgical wound infections despite increasing antibiotic resistance. Eur J Clin Microbiol Infect Dis. 2002;21:553-6.

11. Fitzgerald KA, Davies A, Russell AD. Mechanism of action of chlorhexidine diacetate and phenoxyethanol singly and in combination against gram-negative bacteria. Microbios. 1992;70:215-30.

Cite this article as: Kesani VP, Talasila S, Sheela SR. Chlorhexidine-alcohol versus Povidone-Iodinealcohol for surgical site antisepsis in caesarean section. Int J Reprod Contracept Obstet Gynecol 2019;8:1359-62. 